\title{
Encapsulated Thymoma
}

National Cancer Institute

\section{Source}

National Cancer Institute. Encapsulated Thymoma. NCI Thesaurus. Code C7386.

A thymoma that is confined within the capsule and may display benign or malignant morphologic characteristics. 